moratorium". But the moratorium does not apply to whales taken under scientific permit; nor to IWC members that filed objections to it (Norway); nor to whales allocated by the IWC for aboriginal whaling (Greenland, US and Russian Inuits, and so on). The authors also did not mention that 1,000 minkes annually are hardly a statistical blip in a population of more than one million. And they did not explain why they concluded that a "genetic monitoring programme is necessary" because 1,000 minke whales were taken legally.

Finally, Cipriano and Palumbi are wrong to characterize legal rights and obligations as "loopholes... large enough for protected whales to slip through". The catch and identification of a blue/fin hybrid whale advanced scientific knowledge of a species interaction that most scientists had not thought possible. Similarly, the Japanese discovery of a pygmy minke whale species and its minke stock identifications in the Antarctic were significant contributions to science. Would Cipriano and Palumbi ban this type of science to close their "loophole"?

As for the Convention on International Trade in Endangered Species (CITES), more countries would support it if it were more scientifically based and less driven by animal-rights lobbyists. That is why most countries are now trying to reform it.

Alan Macnow

Japan Whaling Association,

321 East 53 Street, New York 10022, USA

Palumbi and Cipriano reply - In our view, Macnow does not advance the debate about the role of genetics in whaling or deal with the substantial issues that face efforts to manage international marine resources, nor does he question our results. Our data show how genetic techniques can lead to a positive identification of a particular whale sample. Such an identification system provides the ability to trace an individual from ocean to retail market. This pathway is the focus of all international efforts to manage whaling, but it has never been directly observed until now. Instead, typical management efforts use indirect measures of stock levels and total fishery impact.

The points raised by the Japan Whaling Association via Macnow's letter do not address these issues. Rather, the main point seems to be that whales are not protected because mechanisms such as scientific whaling exist to allow countries to ignore IWC restrictions. Yet the mere fact that a permit is required to conduct scientific whaling shows that the IWC intends to protect species that have been overexploited until populations have recovered.

It may be that the association wishes to conclude that no whale is protected once it has been targeted by a scientific whaling operation because such operations have no clear bounds. The loose regulations on scientific whaling have been the subject of much debate in the IWC, in Nature and elsewhere. Despite the provisions for scientific whaling, IWC and CITES regulations are clearly designed to protect whale stocks from overexploitation. Macnow's opinion that no whales are "protected" is ironically close to our own point that current international regulations allow individuals of species in need of protection to be killed and sold legally.

Macnow also does not accurately represent our call for genetic databases. Our market surveys since 1993 have shown many species available in markets, not just the minke whales taken for research. We recommend a genetic monitoring programme precisely because it is impossible to prove that these whales come from illegal sources without a genetic database of legally taken whales.

However, we are very encouraged by the promise of the Japan Whaling Association not to allow the import of whale products from Iceland, especially after Iceland's decision on 10 March to resume commercial whaling.

Finally, Macnow implies that much scientific whaling is done for valid experimental purposes. This is an important but controversial topic, and Macnow does not provide any solid evidence of the value of data gathered. In fact, non-lethal methods of research have developed quickly over the past decade, and have supplanted the need to kill whales in many instances. Genetic samples from skin biopsies, sloughed skin or even faeces now provide a wealth of information about stock structure that in the past has been provided by liver samples from scientific hunts. Steve Palumbi, Frank Cipriano

Department of Organismic and Evolutionary Biology, Harvard University, BioLabs, 16 Divinity Avenue, Cambridge, Massachusetts 02138, USA

\section{System values seniority over innovation}

Sir - As a postdoctoral researcher I can identify with many of the feelings expressed in your poll of postdocs (Nature 397, $640-641 ; 1999)$. My biggest frustration is with the problem of obtaining external funding. I am sick of having to use a professor's name on research proposals to get them funded.

If I want the all-important funding I have to donate my ideas to a more senior researcher. I receive no recognition, and my control of the budget, and therefore the research design and implementation, is reduced. I currently work in Sweden, and my friends in Britain mirror my concerns.

It seems that funding councils, staffed by senior researchers, impose a system in which seniority overrides innovation and enthusiasm, and young researchers are open to exploitation. Presumably, should I reach those dizzy heights, I will be expected to boost my research profile in the same way. The system blocks my ideas and career development for those of a professor who, incidentally, I have no doubt is in sympathy with my concerns.

I. A. Brown

Climate Impacts Research Centre, Björkplan 6a, 98142 Kiruna, Sweden

\section{Curb abuses in graduate school}

Sir - Carl Djerassi's Commentary makes the most insightful and useful suggestion I have seen on the issue of mentoring in graduate school (Nature 397, 291; 1999).

Djerassi calls for the candid evaluation of professors as research administrators and mentors, a proposal that might genuinely improve the lives of graduate students. $\mathrm{He}$ has taken a bold step in addressing this issue squarely and honestly.

I am in a graduate programme at Harvard University that has long employed advisory committees, and the difficulties with them are exactly as Djerassi says. Senior members of faculty hold complete sway over these committees, and other committee members contest the opinion of these individuals at their peril. The committee system is in no way independent or objective, nor does it provide the opportunity to discern, let alone to correct, conflicts or deficiencies in the working relationship between professors and graduate students.

It is widely agreed among graduate students here that Jason Altom would have been no better off with a committee than he was without one. Perhaps this is also recognized by faculty members, but Djerassi is the first to acknowledge it in my experience.

Many students will suffer in their careers, or be driven to abandon science altogether, because of difficulties and abuses in graduate school. In addition to the personal suffering that this engenders, it is an enormous waste of scientific talent. Any effort to provide graduate students with fair, reasonable and considerate advice will not only improve their lot but will be positively reflected in the manner in which they conduct themselves throughout their careers and in their relationships with colleagues and students of their own.

Name and address supplied 